\title{
ACADEMIC TRACK OF FOSS4G 2019 BUCHAREST - THE ASYMPTOTIC CONNECTION BETWEEN SOFTWARE AND DATA
}

\author{
A.F. Marin ${ }^{1}$, M.A. Brovelli ${ }^{2 *}$ \\ ${ }^{1}$ Department of Geomorphology-Pedology-Geomatics, Faculty of Geography, University of Bucharest, Romania, \\ andreea.marin@geo.unibuc.ro \\ ${ }^{2}$ Department of Civil and Environmental Engineering, Politecnico di Milano, Milan, Italy, maria.brovelli@ polimi.it
}

\section{Commission IV, WG IV/4}

KEY WORDS: FOSS4G, Bucharest, Academic Track, Preface

\section{PREFACE:}

FOSS4G stands for Free and Open Source Software for Geospatial. It is the flagship event of OSGeo. Each FOSS4G has its special aura, kindly designed by each Local Organising Committe, sharing the local culture and spirit with the greater community. In 2019 , geo-spatial.org, the OSGeo Local Chapter of Romania, won the honour of organising the geospatial event of the year. FOSS4G 2019 was held in Bucharest (Romania), in three of the most important buildings of this city: National Theatre of Bucharest, InterContinental Hotel and Faculty of Geography from the University of Bucharest.

Following the established tradition of FOSS4G conferences, at the 2019 edition, an Academic Track ran in parallel with the General Track. The main purpose of this track was to bring together researchers, teachers, developers, users and practitioners carrying out research activities in geospatial domains, with an emphasis on the open source solutions. All types of topics such as results achieved, case studies, work in progress, academic endeavours to conceptualize, assess or teach open source geospatial software and data, were welcomed. The Academic Committee discouraged prevalent presentations of technologies or use cases without properly justifying originality to the scientific state of the art, emphasizing on particular novelty.

At this edition, 53 papers were submitted to the Academic Track. These were blind reviewed by 3 reviewers. Finally 38 scientific papers were selected for publication in this volume of the ISPRS Archives. The editors would like to thank all the authors, the members from the Scientific Committee and the Organizing Committee for their valuable contributions. We hope you enjoy reading the proceedings.

\section{Academic Committee Co-Chairs}

Andreea Florentina Marin, University of Bucharest, Romania Maria Antonia Brovelli, Politecnico di Milano, Italy

\section{Academic Committee}

Sergio Acosta Y Lara, Departamento de Geomatica, Direccion Nacional de Topografia, Uruguay

Florina Ardelean, Faculty of Chemistry, Biology and Geography, The West University of Timisoara, Romania

Andy Anderson, Amherst College and University of Massachusetts Amherst, United States

Marius Budileanu, Faculty of Geography, University of Bucharest, Romania

Serena Coetzee, University of Pretoria, South Africa

Sorin Constantin,Terrasigna, Romania

\footnotetext{
* Corresponding author
} 
Ștefan Constantinescu, Faculty of Geography, University of Bucharest, Romania Ionuț Iosifescu, Swiss Federal Research Institute WSL, Switzerland

Ivana Ivanova, Curtin University, Australia

Dimitris Kotzinos, University of Cergy-Pontoise, France

Helena Mitasova, North Carolina State University, United States

Peter Mooney, Department of Computer Science Maynooth University, Ireland Msilikale Msilanga, University of Turku, Finland

Mihai-Daniel Niță, Faculty of Silviculture and Forest Engineering, University of Transilvania Braşov, Romania

Victoria Rautenbach, Department of Geography, Geoinformatics and Meteorology - University of Pretoria, South Africa Charlie Schweik, University of Massachusetts Amherst, United States

Zoltan Siki, Budapest University of Technology and Economics, Hungary

Toung-Thuy Vu, Hoa Sen University, Vietnam

Mohammed Zia, GIScience Research Group - University of Heidelberg, Germany 